\title{
The Relationship between Experienced Respiratory Symptoms and Health-Related Quality of Life in the Elderly with Chronic Obstructive Pulmonary Disease
}

\author{
Daryadokht Masror-Roudsary $\left(\mathbb{D},{ }^{1}\right.$ Nasrin Fadaee Aghdam $\left(\mathbb{D},{ }^{2}\right.$ Forough Rafii $\left(\mathbb{D},{ }^{3}\right.$ \\ Robabe Baha $\left(\mathbb{D},{ }^{4}\right.$ Mahboobeh Khajeh $\left(\mathbb{0},{ }^{2}\right.$ and Abbas Mardani $\mathbb{C}^{5}$ \\ ${ }^{1}$ School of Nursing and Midwifery, Iran University of Medical Sciences, Tehran, Iran \\ ${ }^{2}$ School of Nursing and Midwifery, Shahroud University of Medical Sciences, Shahroud, Iran \\ ${ }^{3}$ Nursing Care Research Center, Iran University of Medical Sciences, Tehran, Iran \\ ${ }^{4}$ Tehran University of Medical Sciences, Tehran, Iran \\ ${ }^{5}$ Nursing Care Research Center, Department of Medical Surgical Nursing, School of Nursing and Midwifery, \\ Iran University of Medical Sciences, Tehran, Iran \\ Correspondence should be addressed to Nasrin Fadaee Aghdam; fadae_n@shmu.ac.ir
}

Received 27 January 2021; Accepted 4 May 2021; Published 13 May 2021

Academic Editor: Thomas Esposito

Copyright (C) 2021 Daryadokht Masror-Roudsary et al. This is an open access article distributed under the Creative Commons Attribution License, which permits unrestricted use, distribution, and reproduction in any medium, provided the original work is properly cited.

\begin{abstract}
Background. Chronic obstructive pulmonary disease (COPD) is one of the diseases that usually present at an advanced age. Respiratory symptoms in patients with COPD are the most important for making treatment decisions and understanding the adverse effects on health-related quality of life (HRQoL). This study aimed to investigate HRQoL in elderly patients with COPD and examine the relationship between this in relation to respiratory symptoms experienced by them and their demographic characteristics. Methods. This is a descriptive, correlational study of elderly patients with COPD who were hospitalized in five different hospitals in an urban area of Iran. A consecutive sampling method was used. Demographic data form, the respiratory symptoms component of St. George's Respiratory Questionnaire (SGRQ), and the Short Form 36 Health Survey Questionnaire (SF-36) were applied for data collection. Results. The patients $(n=217)$ reported low HRQoL, and this impairment was more observed in the physical component. There was a significant inverse relationship between the experienced respiratory symptoms and physical $(p=0.03)$ and mental $(p<0.001)$ components of HRQoL. Moreover, the female gender, the low level of education, the increased duration of the disease, the increased number of hospitalizations during the past year, and the use of two classes of drugs simultaneously were associated with the impaired HRQoL. Conclusion. Our findings inform healthcare providers about the negative impacts of respiratory symptoms and other related factors on the HRQoL of elderly patients with COPD. Nurses and other healthcare providers should proactively identify respiratory symptoms and design appropriate caring strategies to improve HRQoL among this group.
\end{abstract}

\section{Introduction}

The world's elderly population is growing, which is anticipated to increase from 15.7 percent in 2020 to 25 percent up to 2030 [1]. Various criteria confirm successful aging, including not having any diseases such as cancer, cardiovascular and respiratory diseases, and diabetes; good physical and cognitive functions; good mental health as having no depressive symptoms; and lack of physical disability such as inability to walk and ability to do physical activity without receiving any support [2]. However, the phenomenon of aging is known as the most important factor in the incidence and progression of chronic diseases [3]. One of the diseases occurring during this period is chronic obstructive pulmonary disease (COPD), which is a chronic and progressive obstruction of the airway leading to breathing disorder [4]. 
This disease includes emphysema and chronic bronchitis. It is predicted that, by 2030, this disease will be accounted for seven of the top ten leading causes of disease burden [5] and will reach the third leading cause of death worldwide [6]. Moreover, this disease is one of the major causes of mortality associated with high economic and social costs [7].

Primary symptoms of COPD include shortness of breath, cough, increased sputum, wheezing, and chest congestion. Secondary consequences of the disease include sleep disorders, increased anxiety, and depression that are represented by fatigue, anorexia, and weight loss [8]. Moreover, previous studies have shown that respiratory symptoms particularly frequent coughs and shortness of breath are associated with urinary incontinence in elderly patients with COPD [9-11]. Moreover, elderly patients with COPD experience more respiratory symptoms and physical dysfunction with the exacerbation and the increased duration of the disease [12]. Furthermore, exacerbation of the disease can be associated with some other conditions such as sudden cardiac death, which shows that the impacts of COPD are not limited to the respiratory system [13]. Drug treatments in these patients have the main aims of controlling symptoms, reducing the frequency of disease exacerbation, and improving patients' performance and quality of life $[13,14]$. However, it can be associated with serious complications such as osteoporosis [15]. Therefore, the need for proper planning for the proper management of these patients is strongly felt.

Undesirable experiences during the elderly life can lead to depression, isolation, substance abuse, and loss of leisure activities and well-being [16]. COPD, its burden, and the consequences of its treatment or nontreatment can greatly affect the life of the elderly [17]. One of the indicators of the disease's burden is health-related quality of life (HRQoL) assessment [18]. HRQoL includes various dimensions such as physical, social, and mental well-being, which are very different for each patient [19]. HRQoL in patients with COPD is closely related to shortness of breath; physical activity disorders; and mental problems such as depression, anxiety, and other psychological disorders [20].

Maintaining a good HRQoL can be known as the main solution to deal with major life changes and problems [16]. Limited studies have examined the quality of life in the elderly with COPD, and the relationship between its symptoms and HRQoL has not been fully investigated in any of the cases yet. Therefore, this study aimed to investigate HRQoL in elderly patients with COPD and examine the relationship between it in relation to respiratory symptoms experienced by them and their demographic characteristics.

\section{Materials and Methods}

2.1. Study Design and Participants. This descriptive, correlational study was performed on elderly patients with COPD who were hospitalized to the selected five referral hospitals in an urban area of Iran. The inclusion criteria were the diagnosis of chronic obstructive pulmonary disease recorded in the medical file and age over 60 years. The exclusion criteria included cooccurrence of other infectious lung diseases (according to the diagnosis recorded in the patient's medical file) with COPD and having physically and mentally debilitating diseases.

The required sample size for the current study was estimated to be 210 according to a similar study [13] with $90 \%$ test power and 95\% confidence level while it was assumed that the correlation coefficient between respiratory symptoms and their HRQoL be at least 0.22 to be statistically significant. The samples were selected using the consecutive sampling method from the patients who were referred to the pulmonary ward of the study hospitals.

2.2. Data Collection Tools. Demographic data form, the respiratory symptoms component of St. George's Respiratory Questionnaire (SGRQ), and the Short Form 36 Health Survey Questionnaire (SF-36) were used for data collection.

The demographic data form contained questions about patients' age, gender, marital status, educational level, COPD type, disease duration, number of hospitalizations during the past year, medication type, comorbidity, and smoking history.

The respiratory symptoms component of the SGRQ was used to assess respiratory symptoms in this study. This questionnaire includes 3 components of respiratory symptoms, activities, and impact. The symptoms' component contains 7 questions on frequency and severity of the experienced respiratory symptoms in the last three months, including cough, sputum production, shortness of breath, attacks of wheezing, good days with few respiratory symptoms, wheezing in the morning, and attacks of chest trouble during the last year. In this questionnaire, the symptom score increases with increasing intensity and repetition. Accordingly, a score of zero indicates the absence of respiratory symptoms and 100 indicates the highest severity of the respiratory symptoms experienced. In the study by Al-Shair et al., the reliability of the questionnaire was calculated by evaluating the internal consistency, and Cronbach's alpha coefficient of the symptoms' component was calculated to be 0.77 [21]. In addition, in Iran, its validity and reliability were evaluated, its reliability was evaluated by assessing the internal correlation of the questions, and Cronbach's alpha coefficient was calculated for the symptoms' component equal to 0.76 [22].

The SF-36 was used to assess HRQoL in the present study. This questionnaire is divided into two main components: physical component summary (PCS) and mental component summary (MCS). PCS includes the subscales of physical functioning, role limitations due to physical problems, bodily pain, and general health perceptions. MCS includes the subscales of social functioning, role limitations due to emotional problems, vitality, and perceived mental health. The total score of each subscale is converted to ranges from 0 to 100 . The zero score shows the worst condition and 100 indicates the best condition on the scale. The validity and reliability of the English version of this questionnaire have been confirmed by many studies in different populations [23, 24]. Additionally, the reliability of the Persian version of this 
questionnaire was evaluated by assessing the internal consistency, and Cronbach's alpha coefficient was calculated to be in the range from 0.77 to 0.90 [25].

2.3. Data Collection. Questionnaires were completed by the researchers through the interview with elderly patients with COPD who had met the eligibility criteria. The interviews were conducted in a private location of the pulmonary wards of the study hospitals. Participants provided written consent to participate after being informed about the aims of the study. In addition, participants were informed that they could leave the study at any time without penalty.

2.4. Ethical Considerations. Ethical approval for this study was obtained from the ethical committee of Tehran University of Medical Sciences under the code of 90/D/130/1317.

2.5. Data Analysis. Data were analyzed using SPSS software, version 25. Descriptive statistics including the mean (standard deviations) for continuous variables and frequency (percentage) for categorical variables were applied to summarize the data. The independent samples $t$-test and one-way ANOVA test were used to investigate the relationship between total HRQoL and demographic characteristics. Furthermore, the independent samples $t$-test was applied to investigate the association between HRQoL and respiratory symptoms. Moreover, multivariable linear regression was conducted to investigate the association between gender, number of hospitalizations within the last year, duration of the disease, and experienced respiratory symptoms and HRQoL. A $p$ value less than 0.05 was considered as a significance level.

\section{Results}

A total of 217 elderly patients participated in this study, of which 55 patients $(25.3 \%)$ were women and $162(74.7 \%)$ of them were men. The mean duration of the disease was 7.1 years with a standard deviation of 9.2 years. This mean was significantly higher in female patients $(9.4 \pm 11.8)$ compared to men $(6.7 \pm 7.9)(p=0.03)$. More than three-quarters of patients $(n=167)$ were suffering from both chronic bronchitis and emphysema. More than $63 \%(n=138)$ of patients had a history of smoking. Other demographic characteristics are presented in Table 1 .

The mean total HRQoL scores of the patients were $41.25 \pm 18.2$. The mean PCS was $33.9 \pm 17.8$, which was significantly lower than MCS $(49.0 \pm 23.6) \quad(p<0.001)$. Univariate analyses showed that gender and educational level also affected patients' HRQoL $(p=0.04)$. In addition, the duration of the disease $(p=0.01)$, the number of hospitalizations during the past year $(p=0.001)$, and the use of two classes of drugs simultaneously $(p=0.002)$ had significantly affected the mean of HRQoL. Other demographic variables did not have any significant effect on the patients' HRQoL (Table 1).
Although there were differences between the effects of each respiratory symptom on the components of quality of life, attacks of wheezing, attacks of chest trouble during last year, and having good days with few respiratory symptoms were found to be significantly associated with both PCS and MCS of the patients' HRQoL (Table 2).

The multivariable linear regression analysis to examine the relationship between gender, number of hospitalizations within the last year, duration of the disease, and experienced respiratory symptoms and HRQoL is shown in Table 3. An inverse significant association was found between the female gender and PCS of HRQoL $(b=-7.41, p=0.004)$. In addition, there were inverse significant associations between the number of hospitalizations within last year and total HRQoL $(b=-3.22, p=0.003)$, PCS $(b=-4.04, p<0.001)$, and MCS $(b=-3.06, p=0.03)$. Further, an inverse relationship was found between the duration of the disease and total HRQoL $(b=-0.27, p=0.02)$, PCS $(b=-0.24$, $p=0.04)$, and MCS $(b=-0.32, p=0.04)$. Finally, there was inverse relationship between experienced respiratory symptoms and total HRQoL $(b=-0.22, p=0.001)$, PCS $(b=-0.14, p=0.03)$, and MCS $(b=-0.33, p<0.001)$.

\section{Discussion}

This study described HRQoL among elderly patients with COPD and investigated the relationship between their HRQoL in relation to respiratory symptoms experienced by them and their demographic characteristics. The results showed that elderly patients with COPD experienced low HRQoL, and this impairment was more observed in the physical component. Moreover, a significant inverse relationship was found between the experienced respiratory symptoms and physical and mental components of HRQoL.

In this study, participants reported low HRQoL, particularly in the physical dimension. Consistent with our findings, two previous studies showed that elderly patients with COPD suffer from low HRQoL, especially in the physical dimension $[26,27]$. In some other studies, old age was one of the predictors of physical activity [12], which was found to be associated with the decreased quality of life in these patients $[28,29]$. Elderly patients with COPD have less body strength compared to healthy individuals. Moreover, these patients have lower physical function ability than healthy individuals, which affects their health-related quality of life [30]. Therefore, our findings suggest that healthcare providers should pay more attention to the quality of life in elderly patients with COPD especially in the physical dimension.

In the present study, some factors such as female gender, low level of education, increased duration of the disease, and increased number of hospitalizations during the past year were observed to be associated with the impaired quality of life in elderly patients with COPD. In addition, in the present study, impairment in the physical dimension of quality of life and duration of the disease was significantly higher in women than men. In the study by Vasiljević et al., female gender and disease severity were among the predictors of physical activity [12] that in turn can affect the quality of 
TABLE 1: Relationship between demographic characteristics and HRQoL in elderly patients with COPD.

\begin{tabular}{|c|c|c|c|c|}
\hline \multirow{2}{*}{ Variables } & & \multirow{2}{*}{$\mathrm{N}(\%)$} & \multicolumn{2}{|c|}{ HRQoL } \\
\hline & & & Mean \pm SD & $p$ value \\
\hline Gender & $\begin{array}{c}\text { Male } \\
\text { Female }\end{array}$ & $\begin{array}{c}162(74.7) \\
55(25.3)\end{array}$ & $\begin{array}{l}42.6 \pm 18.5 \\
37.1 \pm 16.6\end{array}$ & $0.04^{\mathrm{a}}$ \\
\hline Marital status & $\begin{array}{c}\text { Married } \\
\text { Divorced or widow }\end{array}$ & $\begin{array}{c}175(80.6) \\
42(19.4)\end{array}$ & $\begin{array}{l}42.2 \pm 18.6 \\
37.4 \pm 15.5\end{array}$ & $0.12^{\mathrm{a}}$ \\
\hline Level of education & $\begin{array}{c}\text { None } \\
\text { Primary and middle school } \\
\text { High school and any academic }\end{array}$ & $\begin{array}{c}132(60.8) \\
64(29.5) \\
21(9.7)\end{array}$ & $\begin{array}{l}39.3 \pm 17.0 \\
42.8 \pm 19.0 \\
49.0 \pm 20.0\end{array}$ & $0.04^{\mathrm{b}}$ \\
\hline COPD type & $\begin{array}{l}\text { Chronic bronchitis } \\
\text { Emphysema } \\
\text { Both }\end{array}$ & $\begin{array}{l}26(12) \\
24(11.1) \\
167(77)\end{array}$ & $\begin{array}{l}43.9 \pm 18.4 \\
32.8 \pm 18.2 \\
42.1 \pm 17.9\end{array}$ & $0.07^{\mathrm{b}}$ \\
\hline Disease duration & $\begin{array}{c}\text { Up to one year } \\
1 \text { to } 15 \text { years } \\
\text { More than } 15 \text { years }\end{array}$ & $\begin{array}{c}57(26.3) \\
131(60.4) \\
29(13.4)\end{array}$ & $\begin{array}{l}45.0 \pm 20.0 \\
41.5 \pm 17.7 \\
32.5 \pm 13.5\end{array}$ & $0.01^{\mathrm{b}}$ \\
\hline Number of hospitalizations in the past year & $\begin{array}{c}\text { One } \\
\text { Two } \\
\text { Three } \\
\text { More than } 3 \\
\end{array}$ & $\begin{array}{l}75(34.6) \\
67(30.9) \\
36(16.6) \\
39(18.0) \\
\end{array}$ & $\begin{array}{l}46.2 \pm 19.4 \\
42.0 \pm 17.3 \\
39.6 \pm 16.0 \\
32.0 \pm 15.7\end{array}$ & $0.001^{\mathrm{b}}$ \\
\hline Medication type & $\begin{array}{c}\text { Bronchodilator } \\
\text { Corticosteroid } \\
\text { Both } \\
\end{array}$ & $\begin{aligned} & 120(55.3) \\
& 2(0.9) \\
& 86(39.6) \\
&\end{aligned}$ & $\begin{array}{l}44.7 \pm 18.8 \\
40.39 \pm 5.3 \\
35.9 \pm 14.8 \\
\end{array}$ & $0.002^{\mathrm{b}}$ \\
\hline Comorbidity & $\begin{array}{l}\text { Yes } \\
\text { No }\end{array}$ & $\begin{array}{l}111(51.2) \\
106(48.8)\end{array}$ & $\begin{array}{l}40.5 \pm 19.3 \\
42.0 \pm 17.0\end{array}$ & $0.5^{\mathrm{a}}$ \\
\hline Smoking history & $\begin{array}{l}\text { Yes } \\
\text { No }\end{array}$ & $\begin{array}{l}138(63.6) \\
79(36.4)\end{array}$ & $\begin{array}{l}40.7 \pm 17.0 \\
42.2 \pm 20.0\end{array}$ & $0.57^{\mathrm{a}}$ \\
\hline
\end{tabular}

COPD: chronic obstructive pulmonary disease; HRQoL: health-related quality of life. ${ }^{a}$ Independent samples $t$-test. ${ }^{b}$ One-way ANOVA.

TABLE 2: HRQoL and experienced respiratory symptoms in elderly patients with COPD.

\begin{tabular}{|c|c|c|c|c|c|c|c|}
\hline \multirow{2}{*}{ Symptoms } & & \multicolumn{2}{|c|}{ Total HRQoL } & \multicolumn{2}{|c|}{ PCS } & \multicolumn{2}{|c|}{ MCS } \\
\hline & & Mean \pm SD & $p$ value $^{\mathrm{a}}$ & Mean \pm SD & $p$ value $^{\mathrm{a}}$ & Mean \pm SD & $p$ value $^{\mathrm{a}}$ \\
\hline Cough & $\begin{array}{l}\text { No } \\
\text { Yes }\end{array}$ & $\begin{array}{l}38.7 \pm 18.7 \\
41.5 \pm 18.2\end{array}$ & 0.5 & $\begin{array}{l}30.3 \pm 16.1 \\
34.3 \pm 18.0\end{array}$ & 0.3 & $\begin{array}{l}49.3 \pm 25.3 \\
48.9 \pm 23.5\end{array}$ & 0.9 \\
\hline Sputum & $\begin{array}{l}\text { No } \\
\text { Yes }\end{array}$ & $\begin{array}{l}43.3 \pm 21.7 \\
41.0 \pm 17.6\end{array}$ & 0.5 & $\begin{array}{c}34.07 \pm 21.7 \\
33.9 \pm 17.3\end{array}$ & 0.9 & $\begin{array}{l}53.9 \pm 26.4 \\
48.3 \pm 23.2\end{array}$ & 0.25 \\
\hline Shortness of breath & $\begin{array}{l}\text { No } \\
\text { Yes }\end{array}$ & $\begin{array}{l}51.9 \pm 28.7 \\
41.0 \pm 17.7\end{array}$ & 0.15 & $\begin{array}{l}47.8 \pm 32.0 \\
33.5 \pm 17.2\end{array}$ & .04 & $\begin{array}{l}59.5 \pm 29.5 \\
48.7 \pm 23.4\end{array}$ & 0.3 \\
\hline Attacks of wheezing & $\begin{array}{l}\text { No } \\
\text { Yes }\end{array}$ & $\begin{array}{l}47.6 \pm 22.1 \\
40.0 \pm 17.1\end{array}$ & 0.02 & $\begin{array}{l}40.6 \pm 23.7 \\
32.6 \pm 16.3\end{array}$ & 0.06 & $\begin{array}{l}56.0 \pm 25.5 \\
47.7 \pm 23.0\end{array}$ & 0.04 \\
\hline Attacks of chest trouble during last year & $\begin{array}{l}\text { No } \\
\text { Yes }\end{array}$ & $\begin{array}{l}44.7 \pm 17.0 \\
39.3 \pm 18.5\end{array}$ & 0.03 & $\begin{array}{l}37.0 \pm 17.6 \\
32.1 \pm 17.8\end{array}$ & 0.04 & $\begin{array}{c}53.7 \pm 22.0 \\
46.3 \pm 24\end{array}$ & 0.03 \\
\hline Having a good day with few respiratory symptoms & $\begin{array}{l}\text { No } \\
\text { Yes }\end{array}$ & $\begin{array}{l}39.2 \pm 17.4 \\
56.4 \pm 17.0\end{array}$ & $<0.001$ & $\begin{array}{l}32.5 \pm 17.0 \\
44.0 \pm 20.7\end{array}$ & 0.002 & $\begin{array}{l}46.1 \pm 22.6 \\
70.0 \pm 20.2\end{array}$ & $<0.001$ \\
\hline Wheezing in the morning & $\begin{array}{l}\text { No } \\
\text { Yes }\end{array}$ & $\begin{array}{l}41.7 \pm 18.6 \\
39.4 \pm 16.4\end{array}$ & 0.4 & $\begin{array}{l}34.6 \pm 18.3 \\
31.1 \pm 15.7\end{array}$ & 0.2 & $\begin{array}{l}49.5 \pm 24.0 \\
47.3 \pm 22.7\end{array}$ & 0.6 \\
\hline
\end{tabular}

COPD: chronic obstructive pulmonary disease; HRQoL: health-related quality of life; MCS: mental component summary; PCS: physical component summary. ${ }^{\mathrm{a} I n d e p e n d e n t ~ s a m p l e s ~} t$-test.

patients' life. In general, women probably are more disturbed in their duties due to having multiple roles in their lives when exposed to the disease, and therefore their quality of life may be more affected [31,32]. Additionally, other studies reported a direct association between education [28] and disease duration [29] with quality of life in patients with COPD, which was consistent with the present study. Patients with a low level of education may have less understanding of the disease process, treatment strategies, and caring programs and may not easily adapt to the disease [33]. Therefore, in the process of patients' education, the level of literacy of patients should be considered in order to provide efficient education that helps to improve their quality of life. 
TABLE 3: Factors affecting the HRQoL in elderly patients with COPD with emphasis on experienced respiratory symptoms.

\begin{tabular}{|c|c|c|c|c|c|c|c|c|c|}
\hline \multirow[b]{2}{*}{ Factors } & \multicolumn{3}{|c|}{ Total HRQoL } & \multicolumn{3}{|c|}{ PCS } & \multicolumn{3}{|c|}{ MCS } \\
\hline & $\mathrm{b}^{\mathrm{a}}(\mathrm{SE})$ & $95 \% \mathrm{CI}$ & $\begin{array}{c}p \\
\text { value }\end{array}$ & b (SE) & $95 \% \mathrm{CI}$ & $p$ value & b (SE) & $95 \% \mathrm{CI}$ & $p$ value \\
\hline Gender (female) & $\begin{array}{c}-4.6 \\
(2.63)\end{array}$ & $-9.86,0.46$ & 0.07 & $\begin{array}{l}-7.41 \\
(2.57)\end{array}$ & $\begin{array}{c}-12.46 \\
-2.37\end{array}$ & 0.004 & $\begin{array}{l}-3.74 \\
(3.47)\end{array}$ & $\begin{array}{c}-10.55 \\
3.06\end{array}$ & 0.2 \\
\hline $\begin{array}{l}\text { Number of hospitalizations within } \\
\text { last year }\end{array}$ & $\begin{array}{l}-3.22 \\
(1.08)\end{array}$ & $\begin{array}{l}-5.35 \\
-1.09\end{array}$ & 0.003 & $\begin{array}{l}-4.04 \\
(1.06)\end{array}$ & $\begin{array}{l}-6.12 \\
-1.95\end{array}$ & $<0.001$ & $\begin{array}{l}-3.06 \\
(1.43)\end{array}$ & $\begin{array}{l}-5.87 \\
-0.25\end{array}$ & 0.03 \\
\hline Duration of the disease & $\begin{array}{l}-0.27 \\
(0.12)\end{array}$ & $\begin{array}{l}-0.52 \\
-0.03\end{array}$ & 0.02 & $\begin{array}{l}-0.24 \\
(0.12)\end{array}$ & $\begin{array}{l}-0.46 \\
-0.02\end{array}$ & 0.04 & $\begin{array}{l}-0.32 \\
(0.16)\end{array}$ & $\begin{array}{l}-0.60 \\
-0.04\end{array}$ & 0.04 \\
\hline Respiratory symptoms & $\begin{array}{l}-0.22 \\
(0.06)\end{array}$ & $\begin{array}{l}-0.35 \\
-0.08\end{array}$ & 0.001 & $\begin{array}{l}-0.14 \\
(0.06)\end{array}$ & $\begin{array}{l}-0.27 \\
-0.01\end{array}$ & 0.03 & $\begin{array}{r}-0.33 \\
(0.08)\end{array}$ & $\begin{array}{l}-0.50 \\
-0.15\end{array}$ & $<0.001$ \\
\hline
\end{tabular}

CI: confidence interval; COPD: chronic obstructive pulmonary disease; HRQoL: health-related quality of life; MCS: mental component summary; PCS: physical component summary; SE: standard error. ${ }^{\mathrm{a} C o e f f i c i e n t ~ w a s ~ o b t a i n e d ~ a c c o r d i n g ~ t o ~ t h e ~ m u l t i v a r i a b l e ~ l i n e a r ~ r e g r e s s i o n . ~}$

Our study findings showed that patients who took two classes of drugs (bronchodilators and corticosteroids) at the same time reported lower quality of life. In patients with COPD, medications including bronchodilators, corticosteroids, and combination therapies are started to control respiratory symptoms, prevent exacerbation, and improve their quality of life. However, it has been shown that a large number of people with COPD sometimes experience respiratory symptoms, despite the chronic use of several medications [34]. Moreover, it was documented that the inhaled corticosteroids are the secondary cause of osteoporosis in elderly patients with COPD [15], which can have a negative impact on their quality of life.

In the present study, there was a significant inverse relationship between the experienced respiratory symptoms and physical and mental components of HRQoL. Similarly, in the study by Moy et al., the presence of shortness of breath was a more important determinant of quality of life compared to the forced expiratory value in one second (FEV1) [35]. In addition, two other studies evidenced that severe respiratory symptoms were associated with poor HRQoL in patients with COPD $[34,36]$.

In the present study, the experience of attacks of wheezing, attack of chest trouble during last year, and having a good day with few respiratory symptoms was associated with both impaired physical and mental components of HRQoL. In addition, the experience of shortness of breath only was associated with the physical component of HRQoL. Similarly, a prior study found that the experience of frequent coughs and wheezing in the previous 12 months is an important risk factor for the low physical and psychological domain of quality of life among the elderly with respiratory diseases [37]. In addition, it has been revealed that the exacerbation of the disease is associated with the low quality of life of patients with COPD [12]. A prior study has revealed that the most worrying symptom affecting the quality of life was shortness of breath [20]. Shortness of breath and attacks and intolerance to physical activity are distressing and debilitating for patients with COPD, eventually leading to the impaired physical activity of patients and affecting their quality of life [38]. Moreover, in many patients, the prognosis of shortness of breath is associated with an increased physiological response to fear and activation of fear-related areas of the brain. Accordingly, fear increases shortness of breath and avoids physical activity in these patients [39].

Regarding the results of the present study and existing literature, it can be concluded that the physical dimension of quality of life is more impaired in elderly patients with COPD. Due to physical and mental disabilities and lack of adequate social support in old age [40], there are many concerns about the quality of life and providing a dignified life to the elderly [41]. Improving the HRQoL of elderly populations is one of the priorities for the healthcare system worldwide [16]. Previous studies have recommended that using nonpharmacological methods such as counselingbased training programs and breathing exercises may improve the symptoms of the disease, the level of activity tolerance, and the HRQoL in these patients [42]. Light exercises like yoga, which combines movement, controlled breathing, attention, and meditation, can be used in these patients [43]. Yoga affects both physical and mental statuses, and many studies have identified its therapeutic effects on different chronic diseases such as respiratory diseases, diabetes, and high blood pressure [44]. In addition, yoga is associated with an improvement in six-minute walk distance, FEV1, and HRQoL in patients with COPD and is comparable to pulmonary rehabilitation interventions [43].

4.1. Limitations. The present study was a cross-sectional study, and statistical correlations might not always show a cause-and-effect relationship. In addition, the samples in the present study were limited to patients living in an urban area of Iran; therefore, the generalization of the findings to other contexts should be performed with precaution.

\section{Conclusion}

Our study identified that elderly patients with COPD have low HRQoL, and this impairment was more observed in the physical component. Moreover, there was a significant inverse relationship between the experience of attacks of wheezing, attack of chest trouble during last year, and having a good day with few respiratory symptoms and physical and mental components of HRQoL. Furthermore, some factors such as female gender, low level of education, increased duration of the 
disease, increased number of hospitalizations during the past year, and use of two classes of drugs simultaneously were associated with the impaired HRQoL in these patients. Therefore, our findings inform healthcare providers about the negative impacts of respiratory symptoms and other related factors on the HRQoL of elderly patients with COPD. Nurses and other healthcare providers should proactively identify respiratory symptoms and design appropriate caring strategies to improve HRQoL among this group.

\section{Data Availability}

The data used in the study are available upon reasonable request.

\section{Disclosure}

This study was a part of a master thesis supported by the Tehran University of Medical Sciences.

\section{Conflicts of Interest}

The authors declare no conflicts of interest.

\section{Acknowledgments}

The authors thank all participants for their involvement in the study. This study was a part of a master thesis supported financially by the Tehran University of Medical Sciences, Tehran, Iran, under the grant number 90/D/130/1317.

\section{References}

[1] M. K. Lee and J. Oh, "Health-related quality of life in older adults: its association with health literacy, self-efficacy, social support, and health-promoting behavior," Healthcare, vol. 8, no. 4, p. 407, 2020.

[2] B. Gopinath, G. Liew, G. Burlutsky, C. M. McMahon, and P. Mitchell, "Association between vision and hearing impairment and successful aging over five years," Maturitas, vol. 143, pp. 203-208, 2020.

[3] P. De Souto Barreto, S. Guyonnet, I. Ader et al., "The inspire research initiative: a program for geroscience and healthy aging research going from animal models to humans and the healthcare system," The Journal of Frailty \& Aging, vol. 10, no. 2, pp. 86-93, 2021.

[4] F. Cortopassi, P. Gurung, and V. Pinto-Plata, "Chronic obstructive pulmonary disease in elderly patients," Clinics in Geriatric Medicine, vol. 33, no. 4, pp. 539-552, 2017.

[5] N.-F. Yahya, N. Omar, U.-N. Daut, S.-N. A. Adznam, B. Nisak, and M. Yusof, "A systematic review on factors associated with health-related quality of life among chronic obstructive pulmonary disease patients," Malaysian Journal of Medicine and Health Sciences, vol. 15, no. S1, pp. 61-68, 2019.

[6] X. Fang, X. Wang, and C. Bai, "COPD in China," Chest, vol. 139, no. 4, pp. 920-929, 2011.

[7] K. Tachkov, M. Kamusheva, V. Pencheva, and K. Mitov, "Evaluation of the economic and social burden of chronic obstructive pulmonary disease (COPD)," Biotechnology \& Biotechnological Equipment, vol. 31, no. 4, pp. 855-861, 2017.

[8] I. Tsiligianni and J. W. H. Kocks, "Daytime symptoms of chronic obstructive pulmonary disease: a systematic review,"
NPJ Primary Care Respiratory Medicine, vol. 30, no. 1, p. 6, 2020.

[9] F. Hirayama, A. H. Lee, T. Hiramatsu, and Y. Tanikawa, "Breathlessness is associated with urinary incontinence in men: a community-based study," BMC Pulmonary Medicine, vol. 10, no. 2, pp. 1-5, 2010.

[10] F. Hirayama, A. H. Lee, C. W. Binns, H. Taniguchi, K. Nishimura, and K. Kato, "Urinary incontinence in men with chronic obstructive pulmonary disease," International Journal of Urology, vol. 15, no. 8, pp. 751-753, 2008.

[11] Adis Medical Writers, "Manage urinary incontinence in COPD depending on whether it is stress, urge or mixed," Drugs \& Therapy Perspectives, vol. 36, pp. 230-233, 2020.

[12] S. Vasiljevic, M. Petrovic, A. Cvetkovic, V. Paunovic, D. Mikic, and S. Radjen, "Predictors of quality of life of patients with chronic obstructive pulmonary disease," Vojnosanitetski Pregled, vol. 76, no. 7, pp. 716-722, 2019.

[13] A. Corlateanu, V. Botnaru, S. Covantev, S. Dumitru, and N. Siafakas, "Predicting health-related quality of life in patients with chronic obstructive pulmonary disease: the impact of age," Respiration, vol. 92, no. 4, pp. 229-234, 2016.

[14] G. N. Sharma, S. A. Ali, B. Shrivastav, and A. N. Mohd, "Three-drug therapy versus two-drug therapy for management of patient-reported manifestations and quality of life in chronic obstructive pulmonary disease patients: a metaanalysis," Journal of Applied Pharmaceutical Science, vol. 10, no. 10, pp. 36-49, 2020.

[15] S. Ozcakir, D. Sigirli, A. Ursavas, and E. Uzaslan, "COPD and osteoporosis: associated factors in patients treated with inhaled corticosteroids," International Journal of Chronic Obstructive Pulmonary Disease, vol. 15, no. 15, pp. 2441-2448, 2020.

[16] H.-Y. Yen and L.-J. Lin, "Quality of life in older adults: benefits from the productive engagement in physical activity," Journal of Exercise Science \& Fitness, vol. 16, no. 2, pp. 49-54, 2018.

[17] T. R. Fried, C. A. V. Fragoso, and M. W. Rabow, "Caring for the older person with chronic obstructive pulmonary disease," JAMA Journal, vol. 308, no. 12, pp. 1254-1263, 2012.

[18] S. Yin, R. Njai, L. Barker, P. Z. Siegel, and Y. Liao, "Summarizing health-related quality of life (HRQOL): development and testing of a one-factor model," Population Health Metrics, vol. 14, no. 22, pp. 1-9, 2016.

[19] A.-M. Selzler, R. Habash, L. Robson, E. Lenton, R. Goldstein, and D. Brooks, "Self-efficacy and health-related quality of life in chronic obstructive pulmonary disease: a meta-analysis," Patient Education and Counseling, vol. 103, no. 4, pp. 682692, 2020.

[20] T. S. Farag, E. S. M. Sobh, S. B. Elsawy, and B. M. Fahmy, "Evaluation of health-related quality of life in patients with chronic obstructive pulmonary disease," Egyptian Journal of Bronchology, vol. 12, no. 3, pp. 288-294, 2018.

[21] K. Al-Shair, G. T. W. Atherton, D. Kennedy, G. Powell, D. W. Denning, and A. Caress, "Validity and reliability of the St. George's respiratory questionnaire in assessing health status in patients with chronic pulmonary aspergillosis," Chest, vol. 144, no. 2, pp. 623-631, 2013.

[22] S. Fallah Tafti, S. M. Marashian, A. Cheraghvandi, and H. Emami, "Investigation of validity and reliability of persian version of the "St. George respiratory questionaire"” Pajoohandeh Journal, vol. 12, no. 1, pp. 43-50, 2007.

[23] J. E. Ware and B. Gandek, "Overview of the SF-36 health survey and the international quality of life assessment 
(IQOLA) project," Journal of Clinical Epidemiology, vol. 51, no. 11, pp. 903-912, 1998.

[24] A. Bunevicius, "Reliability and validity of the SF-36 health survey questionnaire in patients with brain tumors: a crosssectional study," Health and Quality of Life Outcomes, vol. 15, no. 1, pp. 1-7, 2017.

[25] A. Montazeri, A. Goshtasebi, M. Vahdaninia, and B. Gandek, "The short form health survey (SF-36): translation and validation study of the iranian version," Quality of Life Research, vol. 14, no. 3, pp. 875-882, 2005.

[26] C. H. Shah, R. M. Reed, E. Villalonga-Olives et al., "Quantifying heterogeneity of physical and mental health-related quality of life in chronic obstructive pulmonary disease patients in the United States," Expert Review of Respiratory Medicine, vol. 14, no. 9, pp. 937-947, 2020.

[27] E. Niksarlioglu, B. Yigitbas, G. Çamsari, and F. Kosar, "Health-related quality of life in elderly patients with bronchiectasis," Eurasian Journal of Pulmonology, vol. 22, no. 2, pp. 98-103, 2020.

[28] J. Rosińczuk, M. Przyszlak, and I. Uchmanowicz, "Sociodemographic and clinical factors affecting the quality of life of patients with chronic obstructive pulmonary disease," International Journal of Chronic Obstructive Pulmonary Disease, vol. 13, pp. 2869-2882, 2018.

[29] M. Ahmed, A. Neyaz, and A. Aslami, "Health-related quality of life of chronic obstructive pulmonary disease patients: results from a community based cross-sectional study in Aligarh, Uttar Pradesh, India," Lung India, vol. 33, no. 2, pp. 148-153, 2016.

[30] A. Rafaela, M. João, V. Arrifes, and Â. M. Pereira, "Quality of life in patients with chronic obstructive pulmonary disease," Annals of Medicine, vol. 51, no. 1, pp. 220-221, 2019.

[31] J. P. De Torres, C. Casanova, C. Hernández et al., "Gender associated differences in determinants of quality of life in patients with COPD: a case series study," Health and Quality of Life Outcomes, vol. 4, no. 1, pp. 1-7, 2006.

[32] N. Hassanpour, B. Attar bashi Moghadam, S. Musavi, R. Sami, and E. Entezari, "The relationship between demographic variables, disease severity and quality of life in chronic obstructive pulmonary disease patients," Journal of Modern Rehabilitation, vol. 9, no. 3, pp. 19-26, 2015.

[33] E. López-Pintor, J. Grau, I. González, M. Bernal-Soriano, J. Quesada, and B. Lumbreras, "Impact of patients' perception of COPD and treatment on adherence and health-related quality of life in real-world: study in 53 community pharmacies," Respiratory Medicine, vol. 176, Article ID 106280, 2021.

[34] N. Scichilone, R. Antonelli Incalzi, F. Blasi et al., "Circadian rhythm of COPD symptoms in clinically based phenotypes. results from the STORICO Italian observational study," BMC Pulmonary Medicine, vol. 19, no. 1, p. 171, 2019.

[35] M. L. Moy, J. J. Reilly, A. L. Ries et al., "Multivariate models of determinants of health-related quality of life in severe chronic obstructive pulmonary disease," The Journal of Rehabilitation Research and Development, vol. 46, no. 5, pp. 643-654, 2009.

[36] M. Zafar, "Health-related quality of life in patients with chronic obstructive pulmonary disease in Karachi Pakistan-a cross-sectional study," MAMC Journal of Medical Sciences, vol. 6 , no. 1, p. 17, 2020.

[37] P. Carreiro-Martins, J. Gomes-Belo, A. L. Papoila et al., "Chronic respiratory diseases and quality of life in elderly nursing home residents," Chronic Respiratory Disease, vol. 13, no. 3, pp. 211-219, 2016.
[38] A. Spathis, S. Booth, C. Moffat et al., "The breathing, thinking, functioning clinical model: a proposal to facilitate evidencebased breathlessness management in chronic respiratory disease," NPJ Primary Care Respiratory Medicine, vol. 27, pp. 1-6, 2017.

[39] N. A. Hanania and D. E. O’Donnell, “Activity-related dyspnea in chronic obstructive pulmonary disease: physical and psychological consequences, unmet needs, and future directions," International Journal of Chronic Obstructive Pulmonary Disease, vol. 14, pp. 1127-1138, 2019.

[40] S. S. Tavafian, T. Aghamolaei, and B. Moeini, "Functional independence level of physical activities in elderly people: a population-based study," Payesh (Health Monitor), vol. 13, no. 4, pp. 449-456, 2014.

[41] I. P. S. E. Farias, L. D. A. S. Montenegro, R. L. Wanderley et al., "Physical and psychological states interfere with health-related quality of life of institutionalized elderly: a cross-sectional study," BMC Geriatrics, vol. 20, no. 386, pp. 1-10, 2020.

[42] M. Hindelang, F. Kirsch, and R. Leidl, "Effectiveness of nonpharmacological COPD management on health-related quality of life-a systematic review," Expert Review of Pharmacoeconomics \& Outcomes Research, vol. 20, no. 1, pp. 7991, 2020.

[43] K. Ratarasarn and A. Kundu, "Yoga and tai chi," Current Opinion in Pulmonary Medicine, vol. 26, no. 2, pp. 186-192, 2020.

[44] N. Sharma, "The yoga for physical and mental health-can possibly aid in prevention and management of COVID19 infection?" Dev Sanskriti Interdisciplinary International Journal, vol. 16, pp. 22-31, 2020. 